Medical Principles and Practice
Med Principles Pract 1999;8:40-44

Received: November 9, 1997 Revised: March 8, 1998

\title{
Vitamin A Status in Healthy Kuwaiti Newborn and Their Mother Pairs Selected from a Local Hospital Population
}

\author{
Abdul Majid Molla a Majeda Sabri Hamoud ${ }^{b}$ Wasfi Abdul Jalil ${ }^{b}$ \\ Ayesha Mollac $^{c}$ P.N. Sharma ${ }^{a}$ Brahm Swaroop Srivastava ${ }^{a}$ \\ Departments of Paediatrics, a Faculty of Medicine, Kuwait University and ${ }^{\mathrm{b}}$ Al-Adan Hospital, \\ and ${ }^{c}$ Department of Medical Laboratory Science, Faculty of Allied Health and Nursing, \\ Kuwait University, Kuwait
}

\section{Key Words}

Retinol · Chromatography $\cdot$ Infection

\section{Abstract}

Objectives: Both clinical and subclinical vitamin A deficiency has substantial impact on the mortality and morbidity of infectious diseases among children. We prospectively studied the serum retinol level in 200 neonates and their mothers at the Al-Adan Hospital in Kuwait. Methods: Five millilitres each of cord blood and maternal venous blood were collected at the time of delivery. Serum was separated and transported under specified conditions to the laboratory. Serum retinol was estimated using high performance liquid chromatography. Results: Mean serum retinol levels of both babies and mothers were found to be adequate, being 48 and
\end{abstract}

\begin{tabular}{ll}
\hline KARGER & (1) 1999 S. Karger AG, Basel \\
Fax +41 61 306 1234 34 & \\
$\begin{array}{l}\text { E-Mail karger@karger.ch } \\
\text { www.karger.com }\end{array}$ & $\begin{array}{l}\text { Accessible online at: } \\
\text { http://BioMedNet.com/karger }\end{array}$
\end{tabular}

$57 \mu \mathrm{g} / \mathrm{dl}$, respectively. Significant correlation ( $p<0.01$ ) was obtained between serum retinol levels for the babies and their mothers. Conclusion: The results of this study demonstrate that vitamin A deficiency is not present among the neonates and their mothers studied. A larger population survey is recommended in some high risk areas of Kuwait.

\section{Introduction}

Vitamin A deficiency is one of the major nutritional problems in the world. According to a recent estimate, 25-30 million children suffer annually from vitamin A deficiency. Five million of them develop xerophthalmia and 250,000-500,000 become blind [1]. Vitamin A deficiency occurs largely in underde-

Abdul Majid Molla

Department of Paediatrics

Faculty of Medicine, Kuwait University

PO Box 24923

13110 Safat (Kuwait) 
veloped countries among poorer children whose diets are deficient in carotene-containing vegetables, animal products and fat. Repeated episodes of diarrhoea and other infectious diseases, especially measles, may precipitate keratomalacia [2]. Administration of large doses of vitamin A to children with measles reduces mortality [3,4]. Children with signs of vitamin A deficiency are at higher risk of death than normal children $[5,6]$. Recently, the role of vitamin A in the reduction of child mortality has been increasingly recognized. A controlled field trial in Indonesia reported a $34 \%$ reduction in mortality among pre-school children, when their diet was supplemented with large doses of vitamin A [7]. In India, mortality among pre-school children was lowered by $40 \%$ upon distribution of small weekly doses of vitamin A [8]. More recently, the anti-infective property of vitamin A has received attention. Vitamin A appears to enhance survival during acute phases of severe infection as evidenced by studies on measles. Case fatality among children with moderate to severe measles has been reduced by $50 \%$, through the use of oral vitamin A therapy on admission to hospital $[8,9]$. In survivors, the severity of acute illness is modulated and is associated with rapid recovery [10]. Vitamin A-deficient animals survive longer in germ-free environment than in a conventional environment [11]. Recently, the association between subclinical vitamin A deficiency and respiratory infection among children has been reported. In Kuwait, children with respiratory tract infection occupy almost $20 \%$ of the beds in all hospitals, during every winter. There are no data available on vitamin A status of the Kuwaiti population. Therefore, a pilot study was conducted among Kuwaiti newborns and their mothers to estimate the vitamin A status among this population, before embarking upon an intervention study.

Vitamin A Status in Healthy Kuwaiti Newborn and Their Mother Pairs

\section{Subjects and Methods}

The study was carried out in Al-Adan Hospital, located $40 \mathrm{~km}$ south of Kuwait City, during January 1995 to December 1995. A random paired sample of 200 full-term neonates born by vaginal delivery and their mothers were included in the study. Adan is one of the underprivileged areas in Kuwait and was considered appropriate for this study, as the risk of subclinical vitamin A deficiency is more likely in this population. The study was approved by the Research Review Committee of Kuwait University, which also approved the ethics involved in the study. Informed consent was obtained from the mothers of the newborns.

\section{Laboratory Analysis}

About $5 \mathrm{ml}$ each of cord blood and maternal venous blood were collected at the time of delivery. The samples were divided into a tube containing EDTA for estimation of haemoglobin and haematocrit, and into a neutral tube for estimation of serum retinol. The EDTA sample was sent to the haematology Department at the Al-Adan Hospital and the neutral tube sample was transferred to the Paediatric Departmental Laboratory at the Faculty of Medicine, Jabriya, in a thermos containing ice. Serum samples were separated, flushed with nitrogen gas, and stored at $-70^{\circ} \mathrm{C}$ until retinol estimation was done within 8 weeks of collection. Transportation and serum separation were done within $4 \mathrm{~h}$ of collection. Storage and analysis were done avoiding direct exposure to light. Serum retinol was estimated in duplicates using high performance liquid chromatography according to the method described by Bieri et al. [12]. Quality control serum was analysed for each set of test sera evaluated. The coefficient of variation of the retinol results obtained on different days ranged from 7 to $9 \%$. Haemoglobin and haematocrits were analysed using standard methods at the Al-Adan Hospital laboratories. Serum retinol levels of $<10,10-19$ and $\geq 20 \mu \mathrm{g} / \mathrm{dl}$ were considered as deficient, low, and adequate, respectively.

\section{Statistical Analysis}

SPSS 6.1 on PC WINDOWS program was used for statistical analysis and graphical presentation. Pearson's correlation coefficients were calculated to find out if there was an association between serum retinol level and other variables. 


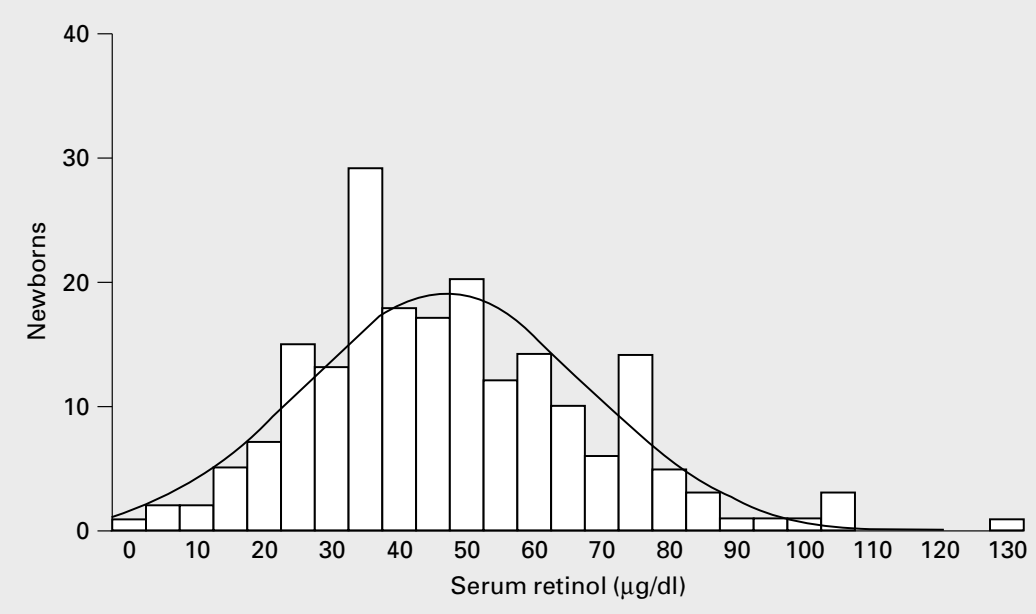

Fig. 1. Distribution of serum retinol among newborn babies.

Table 1. General information of 200 newborns and their mothers included in the study

\begin{tabular}{lrcc}
\hline Variables & Mean & SD & Range \\
\hline Maternal age, years & 27.19 & 6.17 & $17-44$ \\
Pregnancy, n & 2.98 & 2.54 & $1-13$ \\
Maternal Hb, g/dl & 11.64 & 1.38 & $6.30-16.80$ \\
Maternal Hct, \% & 34.87 & 6.9 & $11.20-49.90$ \\
Baby's Hb, g/dl & 14.89 & 1.53 & $10.2-19.10$ \\
Baby's Hct, \% & 44.59 & 8.9 & $32.50-58.40$ \\
Gestation, weeks & 38.95 & 4.77 & $31-42$ \\
Baby's weight, kg & 3.29 & 0.43 & $2.27-4.48$ \\
Maternal serum retinol, $\mu \mathrm{g} / \mathrm{dl}$ & 57.00 & 23.72 & $10.17-183.50$ \\
Baby's serum retinol, $\mu \mathrm{g} / \mathrm{dl}$ & 47.59 & 21.02 & $5.0-132.0$ \\
\hline
\end{tabular}

\section{Results}

The clinical and physical characteristics of the babies and their mothers are presented in table 1. Mean serum retinol levels for both babies and mothers were adequate being 48 and $57 \mu \mathrm{g} / \mathrm{dl}$, respectively. Only 2 of the neonates $(1 \%)$ had serum retinol level of less than
$10 \mu \mathrm{g} / \mathrm{dl}$, which, however was improved to a normal level $(>20 \mu \mathrm{g} / \mathrm{dl})$ as demonstrated by a repeated estimation after 1 month. A histogram with a normal curve for the neonate's serum retinol level is shown in figure 1. Besides a few outliers the distribution of retinol values is normal. A significant $(p<0.01)$ correlation with a correlation coefficient $r=$ 


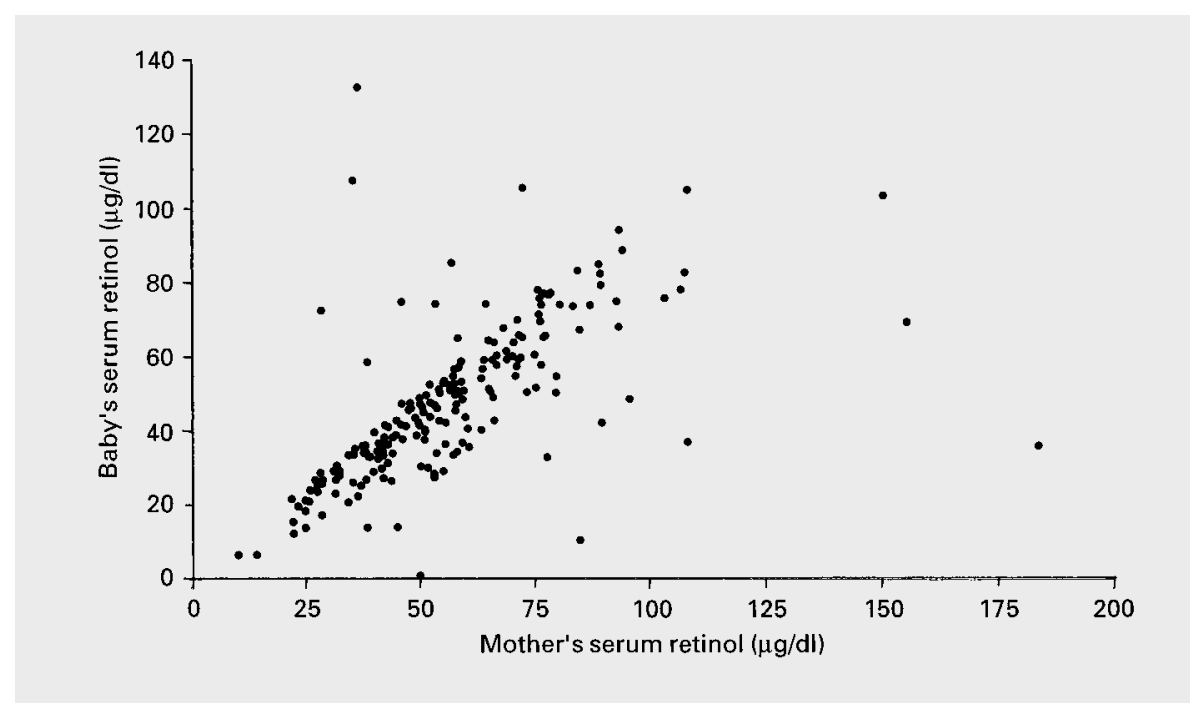

Fig. 2. Correlation between the serum retinol of the newborns and their mothers.

0.614 was obtained between serum retinol levels for the babies and their mothers (fig. 2). There was no correlation between the baby's serum retinol level to their birth weights, or to their mother's age, or haemoglobin levels and number of pregnancies, respectively.

\section{Discussion}

Vitamin A deficiency occurs largely among the children of the poorer countries, where diets are deficient of carotene-containing vegetables, animal products and fat. Repeated episodes of diarrhoea and other infectious diseases deplete the vitamin $\mathrm{A}$ stores and increase the vitamin A requirements [10]. This has been proved by reduction of mortality in children due to pneumonia and measles after supplementation with large doses of vitamin A [3]. Vitamin A supplement has provided substantial positive results only in those countries and among children with gross vitamin $\mathrm{A}$ deficiency, malnutrition and enormous disease burden [11, 12]. More important is the impact of subclinical vitamin A deficiency which is clinically not apparent, but can influence the course and outcome of infectious diseases [13]. It is therefore important to remember that in a country like Kuwait, gross vitamin A deficiency is unlikely to exist. But other nutritional deficiency disease, e.g. nutritional rickets, are not uncommon in Kuwait and some other gulf countries [14, 15]. Patients with nutritional rickets demonstrate deterioration of total nutritional status [16]. The quality of weaning diets of these children is poor. Therefore, it is possible that a specific target group, if studied carefully, may reveal deficiency of vitamin A. The peak incidence of illness among the children due to infections of the respiratory tract in Kuwait, though common throughout the year, occurs during the winter months, e.g. November to February, and most of the paediatric beds are occupied by children suffering from respiratory 
tract illness. Some of these children very often are very sick. The social and dietary habits of the local population are showing a changing pattern with increasing affluency. All sectors of the population do not follow uniform child rearing practices in Kuwait. The weaning diet of young children and its quality has not received adequate attention. Therefore, it is important to carry out a comprehensive study to clearly define that vitamin A deficiency does not exist in this country. The present study, a relatively small one, is unlikely to find vitamin A deficiency in neonates or their mothers. The objective of this study was to assess the status in this specific group of population. A larger study involving children of the vulnerable group is recommended within $\mathrm{Ku}$ wait.

\section{Acknowledgements}

The authors gratefully acknowledge the generous co-operation of Dr. Khidr Al-Najdi, Chairman, Department of Paediatrics, Al-Adan Hospital, during this study.

\section{References}

1 Sommer A: Large dose vitamin A to control vitamin A deficiency. Int $\mathrm{J}$ Vitamin Nutr Res 1989(suppl 30): 37-41.

2 Bloem MW, Wedel M, Egger RJ, Speck AJ, Schrijver JAAP, Kontha SS, Schreurs WHP: Mild vitamin A deficiency and risk of respiratory tract diseases and diarrhea in preschool and school children in Northern Thailand. Am J Epidemiol 1990;131:332-339.

3 Sommer A, Katz J, Tarwotjo I: Increased risk of respiratory disease and diarrhea in children with preexisting vitamin A deficiency. Am J Clin Nutr 1984;40:1090-1095.

4 Hussau GD, Klein MA: A randomized controlled trial of vitamin A in children with severe measles. N Engl J Med 1990;323:160-164.

5 Sommer A, Djunaedi E, Loeden AA, et al: Impact of vitamin A supplementation on childhood mortality. Lancet 1986;i:169-173.

6 Cohen M, Rahman H, Sprague J: Prevalence and determinants of nutritional blindness in Bangladeshi children. World Health Stat Q 1985; 38:317-330.

7 Green HN, Mellanby E: Vitamin A as an anti-infective agent. BMJ 1928;20:691-696.
8 Rahmatullah L, Underwood BA, Thulasiraj RD, Milton RC, Swamy KR, Rahmatuulah R, Babu G: Reduced mortality among children in southern India receiving a small weekly dose of vitamin A. New Engl J Med 1990;323:929-935.

9 Herrera MG, Nestle P, El Amin A, Fawzi WW, Mohammed KA, Weld L: Vitamin A supplementation and child survival. Lancet 1992;340: 267-271.

10 Humphrey JH, West KD Jr, Sommer A: Vitamin A deficiency and attributable mortality under 5 year old. Bull World Health Organ 1992; 70:225-232.

11 Rogers WE, Bieri JG, Mc Daniel EG: Vitamin A deficiency in germ free state; in Deluca HP, Suttie JW (eds): The Fat Soluble Vitamins. Madison, University of Wisconsin Press, 1969, pp 241-255.

12 Bieri JG, Tolliver TJ, Catignani GL: Simultaneous determination of alpha-tocopherol and retinol in plasma and red cells by high pressure liquid chromatography. Am J Clin Nutr 1979;32:2143-2149.
13 Barclays AJG, Foster A, Sommer A: Vitamin A supplements and mortality related to measles: A randomised clinical trial. BMJ 1987;294:294296.

14 Fawzi WW, Herrera MG, Willet WC, Nestle P, Elamin A, Mohammed KA: Dietary vitamin A intake and the incidence of diarrhoea and respiratory infection among Sudanese children. J Nutr 1995;125: 1211-1221.

15 Lubani MM, Shab TS, Al-Saleh QA, Sharda DE, Quattawi SA, Heavy PC: Vitamin D deficiency rickets in Kuwait: The prevalence of a preventable disease. Ann Trop Paediatr 1987;3:134-139.

16 Sidrani SH, Elidrissy AWTH, ElArabi AM: Sunlight and vitamin D status in normal Saudi subjects. Am J Clin Nutr 1983;38:129-132.

17 Elidrissy AWTH: Vitamin D deficiency rickets in Saudi Arabia; in Glorienns FH (ed): Rickets. Nestlé Nutrition Workshop Series. New York, Raven Press, 1991, vol 21, pp 223-233.

18 Molla AM, Badawi M, Yaish S, et al: Nutritional rickets in the children of Kuwait. Abstr Annu Conf Kuwait Med Assoc, 1997. 